\title{
Telangiectasia affected Vater's papilla in Osler Rendu syndrome
}

\author{
Jesús Espinel ${ }^{1}$, Eugenia Pinedo ${ }^{2}$ and Gabriela Rascarachi ${ }^{1}$ \\ ${ }^{1}$ Unit of Endoscopy and ${ }^{2}$ Department of Radiology. Hospital de León. León, Spain
}

\section{CASE REPORT}

52-years-old male diagnosed of Rendu Osler syndrome (ROS) refered dark, pasty stools and anemia (Hg: 9 g/dl). The upper endoscopy revealed a duodenum mucosa with telangiectasias. Afterwards, an enteroscopy was performed and duodenum and jejunum telangiectasias were seen and treated by Argon plasma coagulation. During the procedure one telangiectasia that affected the entire Vater's papilla (Fig. 1A) was identified and confirmed by duodenoscopy (Fig. 1B). The treatment of this particular lesion has been performed as follows: a bile duct cannulation and a subsequent sphincterotomy were done without any incidence. A plastic pancreatic stent was placed and then, the affected papilla's area was treated by Argon coagulation (Fig. 2A). A plastic biliary stent was placed finally. Four days after the procedure, both two stents were removed endoscopically and the disappearance of the papillary telangiectasia was confirmed (Fig. 2B). There were no early or late complications registered (period of follow up: 13 months). The patient has decreased the need for blood transfusions.

\section{DISCUSSION}

The Rendu-Osler syndrome (ROS) is an autosomal dominant vascular disorder with a variety of clinical manifestations. Among the most common are epistaxis, gastrointestinal bleeding, and iron deficiency anemia, along with characteristic mucocutaneous telangiectasia. Telangiectasias occur throughout the gastrointestinal tract, and are more common in the stomach or duodenum. In our case, the main telangiectasia affected Vater's papilla and we decided ablate it in order to prevent bleeding episodes and future possible biliar and pancreatic complications. A sphincterotomy was performed to better asses the extension and depth of the lesion. The biliar and pancreatic plastic stents placement protected both ducts from complications related with the procedure.

Vater's papilla may be involved by benign but potentially dangerous lesions (telangiectasias, polyps, etc), elevating thus the requirement for technical skills and therapeutic tools to allow and guarantee a quick and complications exempted success.

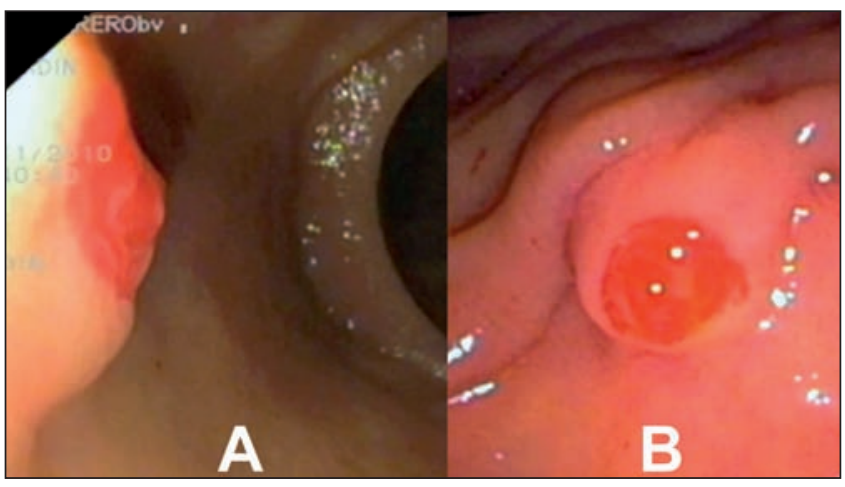

Fig. 1. Duodenal telangiectasia involving the Vater's papilla. A. Frontal view enteroscope. B. Side view duodenoscope.

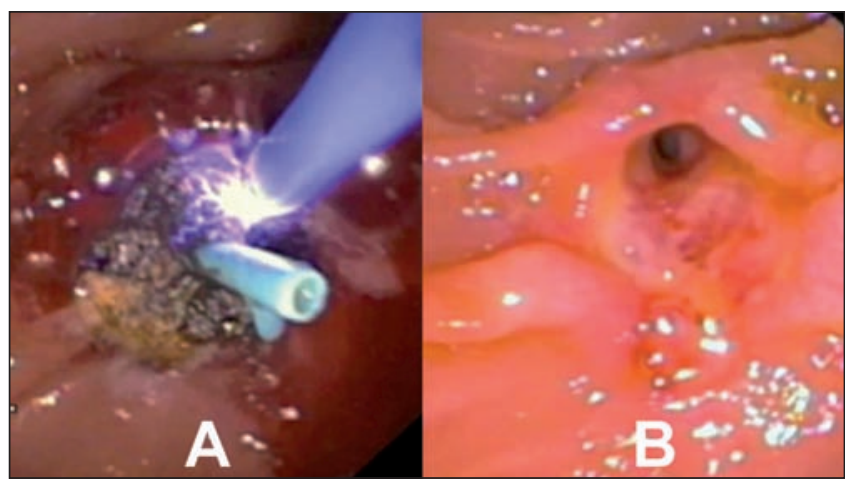

Fig. 2. Papillary telangiectasia ablation with argon. A. Endoscopic control: resolution after ablation $(B)$.

\section{RECOMMENDED REFERENCES}

1. Govani FS, Shovlin CL. Hereditary haemorrhagic telangiectasia: a clinical and scientific review. Eur J Hum Genet 2009;17(7):860-71.

2. Kjeldsen AD, Kjeldsen J. Gastrointestinal bleeding in patients with hereditary hemorrhagic telangiectasia. Am J Gastroenterol 2000;95(2):415-8.

3. Sargeant IR, Loizou LA, Rampton D, Tulloch M, Bown SG. Laser ablation of upper gastrointestinal vascular ectasias: long term results. Gut 1993;34(4):470-5. 